\title{
Covid-19-The Role of Children and Search for Effective Treatment Options with Promising view to Angiotensin II Inhibitors
}

\author{
Stefan Bittmann*, Elisabeth Luchter, Elena Moschüring-Alieva and Gloria Villalon \\ Department of Pediatrics and Ped Mind Institute (PMI), Germany
}

*Corresponding author: Stefan Bittmann, Head of the Department of Pediatrics and Ped Mind Institute (PMI), D-48599 Gronau, Germany

To Cite This Article: Stefan B, Elisabeth L, E Moschüring-Alieva, Gloria Villalon. Covid-19-The Role of Children and Search for Effective Treatment Options with Promising view to Angiotensin II Inhibitors. 2020 - 8(3). AJBSR.MS.ID.001273. DOI: 10.34297/AJBSR.2020.08.001273.

Received: 眥 March 31, 2020; Published: 盖 April 06, 2020

\section{Introduction}

Globally, 462.684 cases of COVID-19 infections have been reported since December 2019, including 20834 deaths (WHO, situation report, date 26/03/2020). 2401 deaths worldwide were found in the last 24 hours (25/3-26/3/2020). These numbers indicate the aggressive and devastating potential of SARS-CoV-2. The first teenager aged 16 died in Paris a few days ago, thus the first COVID 19 positive patient died in France in this age. She had a very short history of dry cough leading to hospitalization and death of around 2 days. In newborns and children no fatal cases are published so far with a moderate course of the disease. According to incomplete statistics, as on February 7, 2020, 285 children with SARS-COV-2 pneumonia and 10 newborns were reported to have been diagnosed in China. No pediatric patient had a fatal outcome, suggesting any "guardian angel“ in children. A new classification of clinical findings and treatment options of SARS-CoV-2 infection in children from China was reported [1].

SARS-CoV-2 uses ACE2 receptor as a portal of entry the lungs [2]. SARS-CoV-2 virus binds to ACE 2 receptor with spike protein [3]. The spike protein has a function polyphasic furin-cleavage site at S1/S2 by insertion of 12 nucleotide and shows mutations at receptor-binding domain (RPD) with binding with 6 RBD amino acids. In children, more than $80 \%$ of Angiotensin II receptors belong to the AT2 subtype, clinically in less severe cases in children. Hypothesis could be more AT1-receptor bindings of COVID 19 like found in adults the more severe case. This hypothesis must be closer analyzed by further molecular studies towards angiotensin
II receptor binding in severe cases, and in children. More than $80 \%$ of pulmonary ACE2 are situated on type II alveolar epithelial cells, those producing pulmonary surfactant [2,3]. A lack of surfactant due to disturbing surfactant synthesis in type II cells should be further closer analyzed. Moreover a lack of surfactant in newborn results in ARDS, like in Covid 19 disease. Clinicians should measure surfactant levels in children and adults. Due to the binding domain at angiotensin II receptor, angiotensin receptor blocker is possible alternatives to treat children with severe Covid 19 infection. To date, there is no clinical experience with COVID 19 positive children, nor any study about that. In adults, a randomized controlled trial (Losartan/Placebo) for 200 patients with severe COVID 19 patients requiring hospitalization was introduced on 16 of March 2020 at the University of Minnesota [4]. Further research should focus on this topic in children.

\section{References}

1. Jiao F, Bittmann S (2020) A new classification of clinical findings and treatment options of SARS-CoV-2 infection in children from China". Advances in Pediatric Research 2020.

2. Nwaiwu O, Olayemi SO, Amao O (2015) Use of angiotensin II receptor blockers in children-a review of evidence“. Niger J Paed 42 (3): 180-187.

3. Flaten HK, Monte AA (2017) The pharmacogenomic and metabolomic predictors of ACE Inhibitor and Angiotensin II Receptor Blocker Effectiveness and Safety“. Cardiovasc Drugs Ther 31(4): 471-482.

4. Clinical Trial. Randomized controlled trial of Losartan for patients with COVID 19 requiring hospitalization", Clinical Trials gov, University of Minnesota, USA. 